\title{
A Quantitative Exploration of Health Care Workers’ Opinions and Attitudes towards HIV-Infected Co-Workers and Patients in Beijing, China
}

Xiaona Liu ${ }^{1,2}$, Xinying Sun ${ }^{1 \#}$, Lenneke van Genugten ${ }^{2}$, Vicki Erasmus ${ }^{2}$, Yuhui Shi', Yanling Wang ${ }^{1}$, Wenyi Niu ${ }^{1 *}$ and Jan Hendrik Richardus ${ }^{2}$

${ }_{1}^{1}$ Department of Social Medicine and Health Education, School of Public Health, Peking University, No.38 Xueyuan Road, Haidian District, 100191 Beijing, China

${ }^{2}$ Department of Public Health, Erasmus MC, University Medical Center Rotterdam, Wytemaweg 80, 3015 CN Rotterdam, the Netherlands

\#Contributed equally to this manuscript

\begin{abstract}
This study examines underlying stigmatizing opinions and attitudes of health care workers (HCWs) that may drive discrimination towards HIV-infected co-workers and patients in the workplace. Socio-demographics, opinions regarding managing HIV-infected co-workers, and attitudes regarding working with HIV-infected patients were measured using a self-administered anonymous questionnaire in a sample of $392 \mathrm{HCWs}$ ( 113 doctors, 236 nurses and 43 technicians) in Beijing. Participants perceived a high risk of HIV transmission in both co-worker and HCW-patient relationships. Half of participants agreed that HCWs should routinely and mandatorily receive HIV-tests, HIV-infected co-workers should disclose their diagnosis to relevant parties, and should be restricted from performing invasive procedures. Most of participants feel disgusted by patients infected through sexual contact, and believed that HCWs have the right to refuse to care for infected patients, and that those patients should be treated only in designated hospitals. Almost all participants intended to avoid performing invasive clinical procedures or nursing services for HIV-infected patients. Nurses had significantly more stigmatizing attitudes towards HIV-infected patients than doctors and technicians. The identified rigid opinions on managing HIV-infected co-workers, together with stigmatizing attitudes towards HIV-infected persons, underscores an urgent need for interventions to prevent discriminatory practices in health care settings.
\end{abstract}

Keywords: Health care provider; Stigma; Employment; Opinion; Discrimination; People living with HIV/AIDS

\section{Introduction}

Health services play a vital role in human immunodeficiency virus (HIV) prevention, treatment and care [1,2]. In China approximately 780,000 individuals lived with HIV/AIDS at the end of 2011 [3]. An increasing number require regular medical investigations and routine health care [4]. As such, health care workers (HCWs) encounter people with HIV, including both HIV-infected co-workers and HIV-infected patients, influencing their work practices and routines [5].

The employment and management of HIV-infected HCWs is a highly debated topic worldwide [6]. Previous international studies $[7,8]$ have indicated that many people have rigid opinions concerning how HIV-infected HCWs should be managed, namely mandatory HIV testing of HCWs, avoidance of performing exposure-prone procedures, and notification of the infection to patients. However, these opinions contradict the UNAIDS recommendations against mandatory testing at recruitment and during employment, restrictions due to HIV/AIDS status, lack of confidentiality regarding HIV/AIDS status, and denial of employment on the grounds of HIV/AIDS status [9]. A qualitative study of doctors with HIV found that many of them struggled with whether, when, how, and what to tell patients regarding their diagnosis [10]. Another study among human resource managers in Singapore showed the dilemmas that organizations face regarding how to balance conflicting interests, namely on the one hand the rights of organizations and their employees with HIV to gain access to AIDS health records, and on the other hand the rights of people with HIV/AIDS to privacy [11]. There is a paucity of reports on managing HIV-infected HCWs in China. Despite the generally strong legislative protection of people with HIV accessing the health care system in China, it is of concern that current Chinese employment laws prevent HIV-infected individuals from professional practices [12], especially medical practices, which might encourage stigma and discrimination and hamper efforts to fight the disease.
Stigma and discrimination are identified as key factors discouraging people with HIV/AIDS from accessing health care services [13], and are thus important contributors to health disparities [14]. Stigma frequently leads to discriminatory practices while discrimination reinforces or creates social and economic inequalities, which then reinforce stigma in a vicious circle $[15,16]$. In health care settings, misconceptions about the disease, fears related to its incurability, and prejudicial attitudes towards risky behaviors have been identified as contributing factors for stigmatizing and discriminatory responses [4]. In China, Eli and colleagues found that $43 \%$ of the general population has a general fear of HIV-infected people [17], and a study by Li and colleagues suggested that HIV-related stigma in health care needs to be addressed at both individual and institutional levels [13]. Previous research in developing countries found that stigmatizing attitudes towards people with HIV among HCWs were positively associated with age [18], and varied by job category. It was found that doctors had the least stigmatizing attitudes as compared to nurses and ward staff [19]. Little is known about stigmatizing attitudes and their correlations among health care staff in China.

Past studies have concentrated on HIV-related stigma and discrimination within health care settings mainly from the perspective

*Corresponding author: Wenyi Niu, Department of Social Medicine and Health Education, School of Public Health, Peking University. No. 38 Xueyuan Road Haidian District, Beijing, China, Tel: 86-10-82801743; Fax: 86-10-82801749; E-mail: health1956@163.com

Received September 21, 2015; Accepted Novmeber 08, 2015; Published November 12, 2015

Citation: Liu X, Sun X, Genugten LV, Erasmus V, Shi Y, et al. (2015) A Quantitative Exploration of Health Care Workers' Opinions and Attitudes towards HIV Infected Co-Workers and Patients in Beijing, China. J AIDS Clin Res 6: 519 doi:10.4172/2155-6113.1000519

Copyright: (c) 2015 Liu X, et al. This is an open-access article distributed unde the terms of the Creative Commons Attribution License, which permits unrestricted use, distribution, and reproduction in any medium, provided the original author and source are credited. 
of patients and the public [20,21]. This study examines personal opinions of Chinese HCWs with regard to their HIV-infected coworkers and attitudes towards their HIV-infected patients. Further, our study describes the associations between socio-demographic factors and personal opinions and attitudes of HCWs. Understanding underlying stigmatizing opinions and attitudes that may drive discrimination are of interest for policy makers, health managers, and health educators, in order to develop and implement effective antidiscrimination interventions in health care settings.

\section{Methods}

\section{Setting and participants}

A cross-sectional survey among $440 \mathrm{HCW}$ sas conducted in Beijing region between May and July 2010. The sample was recruited equally from two tertiary hospitals using a quota sampling technique. Three experienced social medicine researchers first identified all tertiary hospitals in the region, then selected two hospitals to represent the level of medical services and management in urban and suburban areas respectively. The selected hospitals were state-owned, general-referral tertiary hospitals. Finally, to be eligible for the study, participants must have aged 18 or above and were assigned as doctors, nurses or technicians in departments where they are likely to be in contact with blood and sharps, such as internal medicine, surgery, and laboratories. The term 'doctors' in this study refers to those registered with a medical license (including dentists); 'nurses' refers to general nurses or auxiliary nurses; 'technicians' refers to laboratory technicians, assistant technicians and multipurpose support workers. Table 1 includes the demographic data for the participants.

\begin{tabular}{|c|c|c|}
\hline Characteristics & $n$ & $\%$ \\
\hline \multicolumn{3}{|l|}{ Sex } \\
\hline Male & 67 & 17.1 \\
\hline Female & 325 & 82.9 \\
\hline \multicolumn{3}{|l|}{ Age (year) } \\
\hline $18-30$ & 154 & 39.3 \\
\hline $31-40$ & 117 & 29.8 \\
\hline $41-50$ & 93 & 23.7 \\
\hline 51 or older & 28 & 7.1 \\
\hline \multicolumn{3}{|l|}{ Job category } \\
\hline Doctor & 113 & 28.8 \\
\hline Nurse & 236 & 60.2 \\
\hline Technician & 43 & 11.0 \\
\hline \multicolumn{3}{|l|}{ Job grade } \\
\hline Junior & 208 & 53.1 \\
\hline Middle & 162 & 41.3 \\
\hline Senior & 22 & 5.6 \\
\hline \multicolumn{3}{|l|}{ Working site } \\
\hline Hospital_1 & 195 & 49.7 \\
\hline Hospital_2 & 197 & 50.3 \\
\hline \multicolumn{3}{|l|}{ HIV training } \\
\hline Yes & 166 & 42.3 \\
\hline No & 226 & 57.7 \\
\hline \multicolumn{3}{|l|}{ HIV test } \\
\hline Yes & 99 & 25.3 \\
\hline No & 293 & 74.7 \\
\hline \multicolumn{3}{|c|}{ Percutaneous injury } \\
\hline Yes & 316 & 80.6 \\
\hline No & 76 & 19.4 \\
\hline Total & 392 & 100 \\
\hline
\end{tabular}

Table 1. Socio-demographic and clinical characteristics of participants.
Two of the authors trained investigators in survey procedure (e.g., introduction, materials contribution, and data collection) uniformly before performing the field survey. During the field survey, participants were informed verbally of the aims of the survey, their right to refuse, and the time it would take (about 15 minutes). Those who completed the survey received a towel as an incentive. People who did not wish to participate were asked to return the questionnaire unanswered.

\section{Measures}

The survey involved the self-administration of an anonymous questionnaire, which covered the following topics:

(1) Socio-demographic characteristics: sex, age, job category (doctor, technicians, and nurses), job grade (primary, middle, and senior), and working site (hospital 1 and 2).

(2) Opinions about HIV-infected co-workers, containing four dimensions based on Kagan's work regarding managing HIVrelated employment [8]: general attitudes, HIV testing among HCWs, practice restriction, and diagnosis disclosure (9 items in total). Each item includes a statement expressing a rigid opinion against HIV-infected HCWs measured on a 5-point Likert-type scale: $1=$ Strongly disagree; $2=$ Disagree; $3=$ Neutral; 4=Agree; 5=Strongly agree. E.g., "I am not comfortable working with a colleague who is infected with HIV". By dividing the sum of the scores of the 9 items by 9 , we constructed a mean variable indicating overall agreement with rigid opinions regarding the management of HIV-infected co-workers (Cronbach's $\alpha=$ 0.769 ; Residuals were normally distributed, $p>0.05$ ). A higher score indicates more agreement with the rigid statements regarding managing their HIV-infected co-workers.

(3) Attitudes towards HIV-infected patients, containing four dimensions based on the stigmatizing attitude indicators defined in the survey conducted by China HIV/AIDS Media Partnership [22]: disgust, fear, refusal, and avoidance intent (10 items in total). Each item includes a stigmatizing statement presenting negative attitudes against HIV-infected patients measured on the same 5-point Likert-type scale. E.g., "Patients infected with HIV by blood transfusion are disgusting". By dividing the sum score of the 10 items by 10 , we constructed a mean variable indicating the general attitude of HCWs towards HIV-infected patients (Cronbach's $\alpha=0.686$; Residuals were normally distributed, $p>0.05$ ). A higher score indicates more stigmatizing attitudes towards HIV-infected patients.

(4) Whether or not participants received HIV-related training, underwent HIV testing and experienced percutaneous injury during their working lifetime (yes $=1$; no $=0$ ).

The structured questionnaire was improved through a pilot survey among 30 nurses in Beijing, between January and February, 2010. Reliability was improved by deleting items that were not relevant to the scale. Internal consistency was improved by making changes in wording of statements during one round-table meetings in February 2010.

\section{Data analysis and statistics}

All analyses were performed using Statistical Package for the Social Sciences (SPSS Version 20). Descriptive statistics, including frequency, percentage, mean $(M)$ and standard deviation $(S D)$, were calculated to describe the study population, attitudes and opinions of HCWs. Using univariate and multivariable linear regression analyses, regression 
coefficient $(\beta)$ with $95 \%$ confidence intervals $(95 \% \mathrm{CI})$ were obtained to study the association between socio-demographic characteristics, HIV training, HIV testing, percutaneous injury, the general opinion of HCWs on managing HIV-infected co-workers, and the general attitude of HCWs towards HIV-infected patients. Multivariable linear regression models were built using backward stepwise exclusion to study correlates of general opinion and attitudes respectively for variables with a univariate $p$-value $<0.20$ [23]. All statistical tests were two sided. A $p$-value $<0.05$ was considered statistically significant.

\section{Results}

\section{Participants}

Of the 440 questionnaires distributed, 409 (93.0\%) were returned to the investigators and $392(89.1 \%)$ had been completed (195 and 197 from two hospitals respectively). The median age of the sample was 36.2 years (range: 19-64 years). The majority of participants were female (82.9\%), nurses (60.2\%), and holding a non-senior title (94.4\%). Over half of them had not received any HIV-related training during their working lifetime (57.7\%), and had never been tested for HIV (74.7\%). Eighty percent reported that they had experienced at least one percutaneous injury during the working lifetime (Table 1).

\section{Opinions on managing HIV-infected co-workers}

More than $80 \%$ of participants thought that HIV-infected coworkers are dangerous to patients in the workplace, and felt more or less uncomfortable working with them (Table 2). Over half of the HCWs agreed that all HCWs should routinely and mandatorily be tested for HIV (86.2\% and 56.4\%, respectively), and HIV-infected coworkers should not perform any invasive procedure (68.3\%). Half of them (45.4\%) even believed infected HCWs should not carry out any clinic work. In response to questions on disclosure of the diagnosis of HIV-infected HCWs, about half of participants were of the opinion that it should be mandatory for infected HCWs to disclose the fact that they are infected to those in their workplace, including to hospitals managers $(65.0 \%)$ and to patients $(40.8 \%)$, and that patients should be allowed to refuse any procedure performed by infected HCWs (61.5\%). The overall score was 3.68 (95\%CI: 2.52 - 4.83), indicating that participants agreed with most of the rigid statements regarding the management of co-workers infected with HIV.

\section{Attitudes towards HIV-infected patients}

Approximately $80 \%$ of respondents reported that they felt that patients infected with HIV through sexual contact were disgusting, and $86.7 \%$ were afraid of HIV transmission when working with HIVinfected patients (Table 3). Most HCWs believed that they have the right to refuse to care for infected patients (51.8\%), and that those patients should be treated only in designated hospitals $(87.0 \%)$. Almost all HCWs intended more or less to avoid performing invasive clinical procedures or nursing services for HIV-infected patients (91.0\%). However, feelings of disgust were not often found towards patients infected with HIV by blood transmission or for mother-tochild transmission ( $8.9 \%$ and $3.5 \%$, respectively), and few respondents reported an intention to avoid providing general physical examination and care that did not involve bodily contact $(15.5 \%$ and $8.4 \%$, respectively). In general, the overall attitude score was 3.23 (95\%CI: 2.31 - 4.15), indicating stigmatizing attitudes towards patients infected with HIV.

\section{Correlators of general opinions and attitudes}

Univariate linear regression analyses (Table 4) showed that the general opinion of HCWs on managing their co-workers with HIV was more likely to be rigid among participants who had higher job grades $(p=0.02)$, and probably who were female $(p=0.12)$ and younger $(p=$ $0.06)$. However, when these variables were entered in the multivariable model, no statistically significant associations with the general opinion were found $(p>0.05)$. On the other hand, univariate linear regression analyses showed that the stigmatizing attitude towards patients with HIV was more likely to be held by HCWs who were female $(\beta=-0.25$, $p=0.01)$, are nurses $(\beta$ doctor/nurse $=-0.25, p<0.01 ; \beta$ technician $/$ nurse $=-0.19, p=0.01$, and had had a percutaneous injury during their working lifetime $(P=0.02)$, and probably who had senior grade $(P=0.17)$, was working at the suburban hospital $(P=0.13)$. After adjusting for these variable in the multivariable model, nurses retain significantly more stigmatizing attitudes than doctors $(\beta=-0.25, p<$ $0.01)$ and technicians $(\beta=-0.19, p=0.02)$. Sex was excluded from the model because its strong association with job category $(p<0.01)$. The multivariable model explained $12.3 \%$ of the variance in attitudes.

\begin{tabular}{|c|c|c|c|c|c|c|c|c|c|c|c|}
\hline \multirow[t]{2}{*}{ Items } & \multicolumn{2}{|c|}{$\begin{array}{l}\text { Strongly } \\
\text { disagree }\end{array}$} & \multicolumn{2}{|c|}{ Disagree } & \multicolumn{2}{|c|}{ Neutral } & \multicolumn{2}{|c|}{ Agree } & \multicolumn{2}{|c|}{$\begin{array}{l}\text { Strongly } \\
\text { agree }\end{array}$} & \multirow{2}{*}{$\begin{array}{c}\text { Mean } \\
(95 \% \mathrm{Cl})\end{array}$} \\
\hline & $n$ & $\%$ & $n$ & $\%$ & $n$ & $\%$ & $n$ & $\%$ & $n$ & $\%$ & \\
\hline \multicolumn{12}{|l|}{ Stigmatizing attitudes } \\
\hline 1. A HIV-infected HCW is a danger to patients & 1 & 0.3 & 29 & 7.4 & 27 & 6.9 & 161 & 41.1 & 174 & 44.4 & $4.2(4.1-4.3)$ \\
\hline 2. I am not comfortable working with a colleague who is infected with HIV & 10 & 2.6 & 61 & 15.6 & 167 & 42.6 & 104 & 26.5 & 50 & 12.8 & $3.3(3.2-3.4)$ \\
\hline \multicolumn{12}{|l|}{ Testing of HCWs } \\
\hline 3. Routine testing should be adapted among HCWs & 1 & 0.3 & 14 & 3.6 & 39 & 9.9 & 151 & 38.5 & 187 & 47.7 & $4.3(4.2-4.4)$ \\
\hline 4. Mandatory testing should be adapted among HCWs & 11 & 2.8 & 61 & 15.6 & 99 & 25.3 & 105 & 26.8 & 116 & 29.6 & $3.6(3.5-3.8)$ \\
\hline \multicolumn{12}{|l|}{ Restriction on practice } \\
\hline 5. HIV-infected HCWs should not perform invasive procedures & 3 & 0.8 & 46 & 11.7 & 75 & 19.1 & 173 & 44.1 & 95 & 24.2 & $3.8(3.7-3.9)$ \\
\hline 6. HIV-infected HCWs should not carry out any clinical work & 13 & 3.3 & 108 & 27.6 & 93 & 23.7 & 127 & 32.4 & 51 & 13.0 & $3.2(3.1-3.3)$ \\
\hline \multicolumn{12}{|l|}{ Enclosure HIV diagnosis } \\
\hline $\begin{array}{l}\text { 7. HIV-infected HCWs should mandatorily disclose the result of their HIV test to } \\
\text { managers in their working place }\end{array}$ & 7 & 1.8 & 41 & 10.5 & 89 & 22.7 & 162 & 41.3 & 93 & 23.7 & $3.7(3.7-3.8)$ \\
\hline $\begin{array}{l}\text { 8. When performing any invasive procedure, HIV-infected HCWs have to disclose } \\
\text { their diagnosis to patients }\end{array}$ & 14 & 3.6 & 108 & 27.6 & 110 & 28.1 & 105 & 26.8 & 55 & 14.0 & $3.2(3.1-3.3)$ \\
\hline 9. Patients have the right to refuse any procedures done by HIV- infected HCWs & 6 & 1.5 & 44 & 11.2 & 101 & 25.8 & 176 & 44.9 & 65 & 16.6 & $3.6(3.5-3.7)$ \\
\hline General Opinion Score & & & & & & & & & & & $3.7(2.5-4.8)$ \\
\hline
\end{tabular}

Table 2. Opinions of health care workers (HCWs) regarding occupational management towards co-workers with HIV 


\begin{tabular}{|c|c|c|c|c|c|c|c|c|c|c|c|}
\hline \multirow[t]{2}{*}{ Items } & \multicolumn{2}{|c|}{$\begin{array}{l}\text { Strongly } \\
\text { disagree }\end{array}$} & \multicolumn{2}{|c|}{ Disagree } & \multicolumn{2}{|c|}{ Neutral } & \multicolumn{2}{|c|}{ Agree } & \multicolumn{2}{|c|}{$\begin{array}{l}\text { Strongly } \\
\text { agree }\end{array}$} & \multirow{2}{*}{$\begin{array}{l}\text { Mean } \\
(95 \% \mathrm{Cl})\end{array}$} \\
\hline & $n$ & $\%$ & $n$ & $\%$ & $n$ & $\%$ & $n$ & $\%$ & $n$ & $\%$ & \\
\hline \multicolumn{12}{|l|}{ Disgust } \\
\hline 1. Patients infected with HIV by sex trade or multiple sex partners are disgusting & 4 & 1.0 & 23 & 5.9 & 52 & 13.3 & 137 & 34.9 & 176 & 44.9 & $4.2(4.1-4.3)$ \\
\hline 2. Patients infected with HIV by blood transfusion are disgusting & 145 & 37.9 & 165 & 42.1 & 47 & 12.0 & 26 & 6.6 & 9 & 2.3 & $2.0(1.9-2.1)$ \\
\hline 3. Patients infected with HIV from their mother are disgusting & 243 & 62.0 & 101 & 25.8 & 34 & 8.7 & 8 & 2.0 & 6 & 1.5 & $1.6(1.5-1.6)$ \\
\hline \multicolumn{12}{|l|}{ Fear } \\
\hline 4. HIV infected patients put HCWs into a high risk of HIV transmission & 1 & 0.3 & 8 & 2.0 & 43 & 11.0 & 154 & 39.3 & 186 & 47.4 & $4.3(4.2-4.4)$ \\
\hline 5. Hospital admission department must test whether any patient is infected with HIV & 2 & 0.5 & 19 & 4.8 & 64 & 16.3 & 163 & 41.6 & 144 & 36.7 & $4.1(4.0-4.2)$ \\
\hline \multicolumn{12}{|l|}{ Refusal } \\
\hline $\begin{array}{l}\text { 6. HCWs are entitled to refuse providing HIV-infected patients any medical service } \\
\text { that may lead to occupational blood exposure }\end{array}$ & 6 & 1.5 & 57 & 14.5 & 126 & 32.1 & 121 & 30.9 & 82 & 20.9 & $3.6(3.4-3.6)$ \\
\hline 7. HIV-infected patients should be treated only in designated hospitals & 4 & 1.0 & 4 & 1.0 & 43 & 11.0 & 158 & 40.3 & 183 & 46.7 & $4.3(4.2-4.4)$ \\
\hline \multicolumn{12}{|l|}{ Avoidance Intent } \\
\hline $\begin{array}{l}\text { 8. I feel uncomfortable to perform invasive clinical procedures or nursing for HIV } \\
\text { infected patients }\end{array}$ & 15 & 3.8 & 20 & 5.1 & 186 & 47.4 & 123 & 31.4 & 48 & 12.2 & $3.4(3.3-3.5)$ \\
\hline 9. I feel uncomfortable to do general physical examination on HIV infected patients & 56 & 14.3 & 111 & 28.3 & 164 & 41.8 & 48 & 12.2 & 13 & 3.3 & $2.6(2.5-2.7)$ \\
\hline $\begin{array}{l}\text { 10. I feel uncomfortable to do medical care, even with no bodily contact with HIV } \\
\text { infected patients }\end{array}$ & 105 & 26.8 & 124 & 31.6 & 130 & 33.2 & 17 & 4.3 & 16 & 4.1 & $2.3(2.2-2.4)$ \\
\hline General Attitude Score & & & & & & & & & & & $3.2(2.3-4.2)$ \\
\hline
\end{tabular}

Table 3. Attitudes of health care workers (HCWs) regarding medical care for patients with HIV.

\begin{tabular}{|c|c|c|c|c|c|c|c|c|c|c|c|c|}
\hline & \multicolumn{6}{|c|}{ Opinions towards co-workers with HIV } & \multicolumn{6}{|c|}{ Attitudes towards patients with HIV } \\
\hline & \multicolumn{3}{|c|}{ Univariate } & \multicolumn{3}{|c|}{ Multivariable $\left(R^{2}=0.078\right)$} & \multicolumn{3}{|c|}{ Univariate } & \multicolumn{3}{|c|}{ Multivariable $\left(R^{2}=0.123\right)$} \\
\hline & $\beta$ & $95 \% \mathrm{Cl}$ & $p$-value & $\beta$ & $95 \% \mathrm{Cl}$ & $p$-value & $\beta$ & $95 \% \mathrm{Cl}$ & $p$-value & $\beta$ & $95 \% \mathrm{Cl}$ & $p$-value \\
\hline Sex (male/female) & -0.12 & $-0.28-0.03$ & $0.12^{*}$ & -0.13 & $-0.29-0.02$ & $0.09^{*}$ & -0.25 & $-0.37--0.13$ & $0.01^{* * \$ \$}$ & & & \\
\hline Age, year & & & $0.06^{\star}$ & & & 0.21 & & & 0.20 & & & \\
\hline $18-30$ & 0.13 & $-0.10-0.37$ & 0.26 & 0.10 & $-0.17-0.36$ & 0.47 & 0.02 & $-0.17-0.20$ & 0.87 & & & \\
\hline $31-40$ & 0.20 & $-0.04-0.44$ & $0.11^{*}$ & 0.17 & $-0.08-0.43$ & $0.18^{*}$ & 0.13 & $-0.07-0.32$ & 0.20 & & & \\
\hline $41-50$ & -0.01 & $-0.25-0.24$ & 0.97 & -0.01 & $-0.25-0.24$ & 0.99 & 0.12 & $-0.08-0.32$ & 0.23 & & & \\
\hline 51 or older & - & & & & & & - & & & & & \\
\hline Job category & & & 0.33 & & & & & & $<0.01^{* *}$ & & & $<0.01^{* *}$ \\
\hline Doctor & -0.09 & $-0.22-0.04$ & 0.20 & & & & -0.25 & $-0.35--0.15$ & $<0.01^{*+}$ & -0.25 & $-0.37--0.13$ & $<0.01^{* *}$ \\
\hline Technician & -0.09 & $-0.28-0.10$ & 0.33 & & & & -0.19 & $-0.33--0.04$ & $0.01^{* *}$ & -0.19 & $-0.36--0.03$ & $0.02^{* *}$ \\
\hline Nurse & - & & & & & & - & & & & & \\
\hline Job grade & & & $0.02^{* *}$ & & & $0.09^{*}$ & & & $0.17^{*}$ & & & $0.17^{*}$ \\
\hline Junior & 0.02 & $-0.24-0.27$ & 0.91 & 0.11 & $-0.17-0.39$ & 0.44 & -0.01 & $-0.22-0.20$ & 0.92 & 0.20 & $-0.02-0.41$ & $0.07^{*}$ \\
\hline Middle & -0.17 & $-0.29--0.05$ & $0.01^{* *}$ & -0.12 & $-0.26-0.03$ & $0.11^{*}$ & -0.09 & $-0.19-0.01$ & $0.06^{*}$ & -0.00 & $-0.10-0.10$ & 0.97 \\
\hline Senior & - & & & & & & - & & & & & \\
\hline Working hospital & -0.01 & $-0.13-0.10$ & 0.84 & & & & -0.07 & $-0.16-0.02$ & $0.13^{*}$ & -0.03 & $-0.13-0.08$ & 0.62 \\
\hline (urban/suburb) & & & & & & & & & & & & \\
\hline HIV training (yes/no) & 0.02 & $-0.10-0.14$ & 0.77 & & & & 0.06 & $-0.03-0.16$ & 0.20 & & & \\
\hline HIV test (yes/no) & 0.02 & $-0.12-0.15$ & 0.79 & & & & -0.01 & $-0.12-0.10$ & 0.82 & & & \\
\hline Percutaneous injury & 0.04 & $-0.11-0.18$ & 0.63 & & & & 0.14 & $0.02-0.26$ & $0.02^{* *}$ & 0.07 & $-0.05-0.19$ & 0.26 \\
\hline (yes/no) & & & & & & & & & & & & \\
\hline
\end{tabular}

Note: * denotes $p$-value $<0.20$; ${ }^{* *}$ denotes $p$-value $<0.05$;

$\S$ sex was excluded from the multivariable model because its strong association with job category $(p<0.001)$;

$\beta$, regression coefficient. Positive $\beta$ imply greater negative opinions or attitudes for the comparison group than for the reference group.

Table 4. Correlators of opinions and attitudes of health care workers towards their co-workers and patients with HIV

\section{Discussion}

This study reveals that HCWs (doctors, nurses and technicians) in two tertiary hospitals in Beijing held rigid opinions on managing HIV-infected co-workers and stigmatizing attitudes towards HIVinfected patients, which suggest that efforts are needed to overcome potential hostility and stigmatization in hospitals. The identified high risk perception of HIV transmission from HIV-infected HCWs to their co-workers and patients may be a result of the found high rate of percutaneous injury among participants. Following standard precautions has been acknowledged worldwide as fundamental in preventing occupational exposure to blood and other body fluids that are potentially infectious [24]. It is thus also important to improve compliance to standard precautions among HCWs in China.

\section{Opinions on managing HIV-infected co-workers}

The majority of participants believed that HCWs should routinely and mandatorily receive HIV tests, that HIV-infected co-workers should disclose their diagnosis to relevant parties, and be restricted 
from performing invasive procedures. Those identified rigid opinions are similar to the findings in studies conducted in the USA [7] and Israel [8]. Contrary to the major concerns and conservative opinions of the HCWs in our study, many studies conducted elsewhere in the world found that the overall prevalence of HIV infection that occurs through HCW-patient contact is low. Also, the risk of transmission of HIV through HCW-patient contact is low [25]. In view of the limited number of studies in China regarding HCWs with HIV-infection, we believe that more information on managing HCWs with HIV is needed in order to develop a policy or guideline at the national level to cope with the professional and moral dilemmas faced by the HIV-infected health workforce in China, especially the HCWs who are involved in invasive procedures. In addition, as rigid opinions of HCWs towards HIV-infected co-workers were not related to socio-demographic factors, such as age, sex, and job category, future policy or guidelines on preventing discrimination among HCWs should apply to all HCWs.

\section{Attitudes towards HIV-infected patients}

It is of special concern that although HCWs in our study did not show negative feelings towards patients infected with HIV through mother-to-child or blood transfusion transmission, they generally felt disgusted by patients who were infected with HIV through sex. In addition, HCWs showed fear and a refusal to help HIV-infected patients, which is in line with findings from Thailand [26] and Bangladesh [18]. The results of a study by Lin and colleagues [27] suggest that positive feeling (e.g., empathy) is helpful to against refusal. However, we found positive feelings but also high intent refusal to patients in this population. This contradiction could be explained by the incorrect assumption of the HCWs that infection through sex is caused by culturally inappropriate behavior (e.g., commercial and homosexual sex) and is self-inflicted. This assumption makes patients unfavorably subject to moral judgment [13]. There are several possible ways to address the fears of HCWs and decrease the likelihood that HIV-infected patients are refused care, including: establishing an HIV/ AIDS care and management policy, strengthening and mainstreaming HIV counseling, and developing and disseminating information on infection control procedures and the availability of post-exposure prophylaxis [28].

Compared to other HCWs (doctors and technicians), nurses were the most likely to have discriminatory attitudes towards patients based on HIV status, suggesting that special attention should be paid to nurses when developing and implementing anti-discrimination interventions in health care settings. Past research has pointed out that people with higher levels of education demonstrate lower levels of stigma [29], which may explain the attitude differences between nurses, doctors and technicians, as nurses are often relatively less educated [30]. Another interesting finding is that many HCWs in our study believed that patients who are infected with HIV should be treated only in designated hospitals. This contradicts the policy that "medical care should be guaranteed to HIV-infected people as it is to non-HIVinfected people", which was established by the "Recommendations on Management of HIV-Infected Individuals and AIDS Sufferers' in 1999 [31]. The specific use of 'designated hospitals' since 1992 in China's 'Medium Term Program for Prevention and Control of AIDS' for the treatment of HIV-infected patients and carriers is, arguably, a way of improving the quality of treatment they receive by ensuring adequate centralization and specialization of resources [31]. However, the level of ambiguity of the policy has led to discrimination in practice by hospitals that are not 'designated' to treat people with HIV. Therefore, in order to decrease stigmatizing attitudes and prevent discriminatory practices in health care settings, it is crucial to rectify gaps in ethics, legislation, and practice.

\section{Strengths and limitations}

This study provides comprehensive insight in stigmatizing opinions and attitudes of HCWs that may lead to discriminative practices for people with HIV. It is one of the few studies that investigated from the perspective of health professionals themselves about HIV-related employment and discrimination. Yet, several limitations must be considered when interpreting the findings of our study. The study relies on self-reported information, thus answers may suffer from a social desirability bias. The factors we explored explained little of the variations in personal attitudes. Studying other factors, especially previous work experience with people with HIV, the closeness of the relationship (e.g. peer at same ward, acquaintance patient) and environmental factors such as institutional support [4] and social norms [32], may provide more in-depth insight for developing antidiscrimination interventions. In addition, the sample in this study was not a probability sample; it came from two hospitals that provided different quality of health care in rural and suburban areas separately. However, in general the selected two tertiary hospitals in the capital warranted higher level of health care quality and safety than many other general hospitals elsewhere in China [33]. Therefore, the results of the study cannot be directly generalized to other HCWs in China, such as to those working in low-resource hospitals, which are likely to yield more stigmatizing attitudes [29]. On the other hand, the rigid opinions and stigmatizing attitudes among HCWs found in the tertiary hospitals combined with the likelihood of over-reporting socially desired answers may mean that our findings underestimate the actual level of discriminatory opinions and attitudes among HCWs. In any case, the findings reflect an urgent need for interventions to decrease the discrimination of HCWs against people with HIV nationally.

\section{Acknowledgements}

We grateful thank the health care workers who supported this study by their active participation. We also highly appreciate the support provided by the senior administrative staff in both hospitals during the field survey process, and Gerard Borsboom for giving valuable advice regarding data analysis.

\section{Ethical Approval}

The questionnaires were anonymous and were approved by the Ethics Committee of Peking University Health Science Center. The participating hospitals gave permission for the questionnaire to be administered, and verbal informed consent was obtained from all participants. Confidentiality of the participants was ensured at all stages of research and reporting.

\section{Potential conflict of interests}

All authors report no conflicts of interest relevant to this article.

\section{References}

1. Yassi A, O'Hara LM, Lockhart K, Spiegel JM (2013) Workplace programmes for HIV and tuberculosis: a systematic review to support development of international guidelines for the health workforce. AIDS Care 25: 525-543.

2. Gormley W, McCaffery J, Quain EE. Moving forward on human resources for health: next steps for scaling up toward universal access to HIVIAIDS prevention, treatment, and care. J Acquir Immune Defic Syndr 57: S113-S115.

3. Ministry of Health of the People's Republic of China (2012) China AIDS response progress report. Beijing, China: Ministry of Health, China.

4. Li L, Wu Z, Liang LJ, Lin C, Guan J, et al. (2013) Reducing HIV-related stigma in health care settings: a randomized controlled trial in China. Am J Public Health 103: 286-292.

5. Smith DR, Ning W (2010) Emerging workplace issues for Chinese health care workers in the new millennium: HIVIAIDS. Work 37: 297-300.

6. McGoldrick C (2012) HIV and employment. Occup Med (Lond) 62: 242-253. 
Citation: Liu X, Sun X, Genugten LV, Erasmus V, Shi Y, et al. (2015) A Quantitative Exploration of Health Care Workers' Opinions and Attitudes towards HIV-Infected Co-Workers and Patients in Beijing, China. J AIDS Clin Res 6: 519. doi:10.4172/2155-6113.1000519

Page 6 of 6

7. Tuboku-Metzger J, Chiarello L, Sinkowitz-Cochran RL, Casano-Dickerson A Cardo D (2005) Public attitudes and opinions toward physicians and dentists infected with bloodborne viruses: results of a national survey. Am J Infect Control 33: 299-303.

8. Kagan I, Ovadia KL, Kaneti T (2008) Physicians' and nurses' views on infected health care workers. Nurs Ethics 15: 573-585.

9. UNAIDS (2000) Protocol for the Identification of Discrimination against People Living with HIV. UNAIDS, Geneva.

10. Klitzman R, Weiss J (2006) Disclosures of illness by doctors to their patients: a qualitative study of doctors with HIV and other serious disorders. Patient Educ Couns 64: 277-284.

11. Lim VK (2003) Managing HIV at the workplace: An empirical study of HIV and HR managers in Singapore. J Occup Health Psychol 8: 235-246.

12. Burki TK (2011) Discrimination against people with HIV persists in China Lancet 377: 286-287.

13. Li L, Wu Z, Wu S, Zhaoc Y, Jia M, et al. (2007) HIV-related stigma in health care settings: a survey of service providers in China. AIDS Patient Care STDS 21: 753-762.

14. Stuber J, Meyer I, Link B (2008) Stigma, prejudice, discrimination and health Soc Sci Med 67: 351-357.

15. http://www.thecanadianencyclopedia.com/en/article/prejudice-anddiscrimination

16. Parker R (2012) Stigma, prejudice and discrimination in global public health Cad Saude Publica 28: 164-169.

17. Lieber E, Li L, Wu Z, Rotheram-Borus MJ, Guan J; National Institute of Mental Health (NIMH) Collaborative HIV Prevention Trial Group (2006) HIVISTD stigmatization fears as health-seeking barriers in China. AIDS Behav 10: 463471.

18. Mohammad Bellal Hossain, Kippax S (2011) Stigmatized attitudes toward people living with HIV in Bangladesh: health care workers' perspectives. Asia Pac J Public Health 23: 171-182.

19. Mahendra VS, Gilborn L, Bharat S, Mudoi R, Gupta I, et al. (2007) Understanding and measuring AIDS-related stigma in health care settings: a developing country perspective. SAHARA J 4: 616-625.

20. Su X, Lau JT, Mak WW, Chen L, Choi KC, et al. (2013) Perceived discrimination, social support, and perceived stress among people living with HIVIAIDS in China. AIDS Care 25: 239-248.

21. Yang Y, Zhang KL (2004) HIVIAIDS-related discrimination in Shanxi rural areas of China. Biomed Environ Sci 17: 410-417.

22. China HIVIAIDS Media Partnership (2008) AIDS-Related Knowledge, Attitudes, Behavior, and Practices: A Survey of 6 Chinese Cities. Beijing, China.

23. Harrell $F$ (2001) Regression modeling strategies: with applications to linear models, logistic regression, and survival analysis. Springer-Verlag, New York.

24. Gourlay DL, Heit HA (2011) Universal precautions: it's not about the molecule! J Pain 12: 722

25. Perry JL, Pearson RD, Jagger J (2006) Infected health care workers and patient safety: a double standard. Am J Infect Control 34: 313-319.

26. Chan KY, Reidpath DD (2007) Stigmatization of patients with AIDS understanding the interrelationships between Thai nurses' attitudes toward HIVIAIDS, drug use, and commercial sex. AIDS Patient Care STDS 21: 763775.

27. Lin C, Li L, Wan D, Wu Z, Yan Z (2012) Empathy and avoidance in treating patients living with HIVIAIDS (PLWHA) among service providers in China. AIDS Care 24: 1341-1348.

28. Pulerwitz J, Michaelis A, Weiss E, Brown L, Mahendra V (2010) Reducing HIVrelated stigma: lessons learned from Horizons research and programs. Public Health Rep 125: 272-281.

29. ASHM, NCHSR (2012) Stigma and Discrimination around HIV and HCV in Healthcare Settings: Research Report.

30. John B, Wang F, Nancy ER, Zhao X (1992) Gender inequality in urban China: education and employment. Modern China 18: 333-370.

31. Yang Y, Zhang KL, Chan KY, Reidpath DD (2005) Institutional and structura forms of HIV-related discrimination in health care: a study set in Beijing. AIDS Care 17 Suppl 2: S129-140.

32. Babalola S (2007) Readiness for HIV testing among young people in northern Nigeria: the roles of social norm and perceived stigma. AIDS Behav 11: 759769 .

33. Bank TW (2010) Fixing the public hospital system in China. In: Health $P$, and Nutrition East Asia and Pacific Region, editor editors. Washington DC, USA. 